\title{
Information on IMIA
}

\section{International Medical Informatics Association}

\section{BOARD}

President

Antoine Geissbuhler, Switzerland

$2010-2013$

Past President

Reinhold Houx, Germany

$2010-2013$

Secretary

Lyn Hanmer, South Africa

2009 - 2012

Treasurer

Lincoln de Assiss Moura, Brazil

$2007-2013$

Vice Presidents

Medlnfo

Riccardo Bellozzi (2010 - 2013)

Membership

Fernando Martin-Sanchez, Spain (2006 - 2012)

Services

Casimir Kulikowski, United States (2006 - 2012)

Special Affairs

Arie Hasman, The Netherlands (2010 - 2013)

Working \& Special Interest Groups

Hyeoun-Ae Park, Korea (2008 - 2014)

CEO

Peter Murray, United Kingdom

$2010-2015$

IMIA Web site: www.imia.org

\section{IMIA REGIONS}

APAMI: Asia Pacific Association for Medical Informatics Michio Kimura, Japan, Vice President

EFMI: European Federation for Medical Informatics Jacob Hofdilik, The Netherlands, Vice President

HELINA: African Region

Ghislain Kovematchoua, Germany, Vice President

IMIA-LAC: Regional Federation of Health Informatics for Latin America and the Caribbean Carol Hullin, Chile, Vice-President

MEAHI - Middle East Association for Health Informatics Ramin Moghaddam, Iran, Vice President

North American Region

Elizabeth Borycki, Canada, Vice-President

\section{WELCOME TO IMIA!}

\section{General}

The International Medical Informatics Association (IMIA) is the world body for health and biomedical informatics. As an 'association of associations', IMIA acts as a bridging organisation to bring together the constituent organisations and their members. IMIA provides leadership and expertise to the multidisciplinary, health focused community and to policy makers, to enable the transformation of healthcare in accord with the world-wide vision of improving the health of the world population. Inherent in IMIA's role is to bring together, from a global perspective, scientists, researchers, users, vendors, developers, consultants and suppliers in an environment of cooperation and sharing.

IMIA was established as an independent, not for profit organisation under Swiss law in 1989. IMIA was originally founded in 1967 as Technical Committee 4 of the International Federation for Information Processing (IFIP). Since 1979, IMIA has evolved from a Special Interest Group of IFIP to its current status as a fully independent international organisation. It continues to maintain its relationship with IFIP as an affiliate organisation and has an appointed Liaison Officer.

IMIA also has close and collaborative ties with the World Health Organization (WHO) as a NGO (Non Government Organization) with appointed Liaison Officers from both the WHO and IMIA.

The working language of IMIA is English.

\section{Vision}

The IMIA vision is that there will be a world-wide systems approach for healthcare. Clinicians, researchers, patients and people in general will be supported by informatics tools, processes and behaviours that make it easy to do the right thing, in the right way, at the right time to improve health care for all. This systems approach will incorporate and integrate research, clinical care and public health. To achieve this vision it will require everyone being supported by informatics-based information and communication systems and technologies.

IMIA will fulfil its vision by:

- Being the scientific informatics association through which the world's knowledge leaders come together to effectively and efficiently create, assemble, integrate, synthesize or assimilate intellectual knowledge that is required worldwide to advance biomedical informatics in its role of improving health and healthcare.

- Being the informatics association that effectively and efficiently connects people and the nations of the world to be able to accomplish the above purpose.

\section{Membership}

IMIA membership consists of Member Societies, Institutional and Affiliate Members, Honorary Fellows and Corresponding Members.

Member Societies generally represent individual countries, although in special circumstances a country may have more than one member society in IMIA. An IMAI Member Society is a society, or a similar appropriate body, which is representative of the bio-medical, and health informatics activities within a country. In the absence of a member society, IMIA accommodates involvement by individuals through "Corresponding" membership, in particular for developing countries as a means of providing encouragement and support to form a representative member society. IMIA member societies may organise into regional groups. IMIA regions now exist for all parts of the world, ie Asia/Pacific (APAMI), Europe (EFMI), for Latin America and the Car- 
ibbean (IMIA-LAC), Africa (HELINA), the Middle East (MEAHI) and North America. Regions are represented at the IMIA General Assembly and Board by Vice Presidents appointed by their respective regional organisations.

Institutional Members consist of corporations and academic institutions. Corporate members currently include vendor, consulting, technology firms, publishers and national professional organisations. Academic members include universities, medical centres, research centres and other similar institutions. Academic members have recently organised to meet on annual basis in conjunction with the IMIA General Assembly to heighten connectivity and deal with areas of mutual interest.

Affiliate Members consist of international organisations that share an interest in the broad field of health and biomedical informatics. In addition to the WHO and IFIP, the International Federation of Health Information Management Associations (IFHIMA) - formerly the International Federation of Health Records Organizations (IFHRO) - is an affiliate member of IMIA. IMIA's Liaison Officers to WHO (Dr. Antoine Geissbuhler, Switzerland) and IFIP (Dr. Hiroshi Takeda, Japan) are working collaboratively on projects of mutual interest.

Honorary Fellows are individuals who have demonstrated exceptional meritorious service in furthering the aims and interests of IMIA; fellowship is conferred for life.

Working and Special Interest Groups provide opportunities for collaboration among individuals who share common interests in a particular focal field. The Nursing Informatics Special Interest Group (IMIA-NI) holds a triennial congress (the next will be NI2012 in Montreal, Canada - www.ni2012.org), and other groups hold working conferences on leading edge and timely health, medical and bio-medical informatics issues. Current and future activities of the Working and Special Interest Groups are posted on the IMIA website and a summary is included in the IMIA Yearbook.

\section{Governance}

IMIA is governed by a General Assembly, which meets annually. It consists of one representative from each IMIA Member Society and Institutional Member, Honorary Fellows, Chairs of IMIA's Working Groups and a representative from Affiliate Members (the WHO, IFIP, IFHIMA), and each of IMIA's Regions. Only IMIA Member Societies have full voting rights.

The Board of IMIA, elected by the General Assembly, conducts the association's affairs. The day-to-day operations are supported by IMIA's CEO and other staff, who are also responsible for IMIA's electronic services.

The officers of the Board and IMIA's

Vice Presidents vigorously pursue IMIA's mission to:

- Monitor the range of special interest areas and focus support on new developments.

- Capitalize on the synergies and collective resources of IMIA's constituents.

- Minimize fragmentation between scientific and professional medical informaticians.

- Ensure successful adaptation to changes in the medical informatics marketplace and discipline.

- Raise the profile and awareness of IMIA within and outside of the IMIA organisation.

- Encourage cooperation between the scientific and commercial health informatics communities.

- Equitably balance support to emerging and existing IMIA members.

- Establish and maintain cooperation and harmony with organizations that emerge to address medical informatics issues.

- Continue to position IMIA as the gate-keeper for medical informatics issues in the international community.

\section{Towards IMIA 2015 - IMIA Strategy and Transformation}

IMIA's Strategic Plan, 'Towards IMIA 2015', was unanimously approved by the IMIA General Assembly at its meeting at MedInfo2007 in Brisbane, Australia in August, 2007 (and in conjunction with IMIA's 40th birthday). The development of the IMIA Strategic Plan was initiated and lead by Dr. Nancy Lorenzi, IMIA Past President. The Strategic Planning Taskforce represented member societies, working groups, corporations, academic members and IMIA headquarters, and details the vision, guiding principles and strategic framework model [1] for what IMIA should do or become by the year 2015. A subsequent 'Transition Plan' was developed and also approved by the General Assembly; it acts as a flexible roadmap, or bridge, to the future, identifying specific areas of activity to guide and monitor evolution towards achieving the vision outlined in the IMIA Strategic Plan. The IMIA Strategic Plan, 'Towards IMIA 2015', and the Transition Plan are available on the IMIA website, and have been presented, and their development process discussed, in the IMIA Yearbook and other publications $[1,2,3]$. Work will be undertaken in 2011-12 to ensure that the IMAI Strategic Plan remains appropriate to IMIA's needs and aspirations.

As part of the transformation of IMIA [4], the IMIA General Assembly meeting in Hiroshima, Japan in November 2009 approved proposals and a process for the expansion of IMIA's central office facilities and staffing, through a decentralised approach, considering the international scope of IMIA. The development of the new services will be undertaken in accordance with IMIA's financial constraints, and address different sections, such as member services, publication services, conference services, accreditation and international projects, in addition to the "core tasks" on finances and preparing the IMIA Board and General Assembly meetings. With the generous support of the Health On the Net Foundation (HON), an IMIA Institutional Member, the current office address in Geneva has been established, and the post of CEO (formerly Executive Director) has been established to head this work. The main IMIA website has been transitioned to a robust content manage- 
ment system that will allow incremental expansion of services to members and the wider community, and other electronic services are being developed. The IMIA Statutes have been updated and changes were approved at the 2010 IMIA General Assembly meeting in Cape Town, South Africa.

An important aspect of IMIA's development in the next few years will be to develop and strengthen our partnerships and synergies, both within IMIA's community, and by reaching out to other organizations, in particular in the fields of standards and global health. IMIA will also leverage the capacity and diversity of our members and of our regions, which represent the true richness of IMIA. Ina first step to building such partnerships, in late 2011, IMIA signed a Letter of Understanding (LoU) with GHIP (Global Health Informatics Partnership, a wholly-owned subsidiary of AMIA) to collaborate globally to help empower health workers to act locally to improve health and health care delivery. GHIP is an international learning community that, through engagement with institutional stakeholders and individuals, is dedicated to knowledge-transfer activities and supporting a collaborative ecosystem for developing solutions to problems in realworld settings, guided by established informatics principles. IMIA will also build on the strength and domain expertise of its Working Groups and Special Interest Groups: many of them will be commissioned to produce reviews and white papers in their fields of expertise, helping to establish IMIA as a leading voice to inform the various stakeholders and decision-makers with quality information, knowledge and advice.

\section{Medlnfo}

IMIA organises the internationally acclaimed triennial "World Congress on Medical and Health Informatics", MedInfo. MedInfo 2010 was held in Cape Town, South Africa on September 12 - 15, 2010, hosted by the South African Health Informatics Association (SAHIA). This marked the first time that a MedInfo had been held on the African Continent. Previous MedInfo events have been held in Stockholm, Sweden (1974), Toronto, Canada, (1977), Tokyo, Japan (1980), Amsterdam, The Netherlands (1983), Washington, USA (1986), Beijing/Singapore (1989), Geneva, Switzerland (1992), Vancouver, Canada (1995), Seoul, Korea (1998), London, UK (2001), San Francisco, USA (2004), and Brisbane, Australia (2007).

MedInfo 2013 will be held in Copenhagen, Denmark, and starting in 2015, MedInfo will be held every two years. The selection of the host for MedInfo 2015 will be made at the 2011 IMIA General Assembly, to be held in Oslo, Norway.

\section{IMIA Recommendations on Health and Biomedical Informatics Education}

Health and biomedical informatics education has existed now for more than 35 years, and the demand is still expanding worldwide. As the international organization devoted to health and biomedical informatics, IMIA developed recommendations on education in health and medical informatics that were first have been published in 2000 and have been extensively used in the development of programmes of health and biomedical informatics education. Under the leadership of John Mantas, the IMIA recommendations on education have been updated and published [5]. They are available through the IMIA website, and we welcome their re-publication and translation.

\section{IMIA Code of Ethics}

IMIA adopted the "IMIA Code of Ethics for Health Information Professionals" in 2002. The code has been translated into several languages, is being translated into others, and is freely available to the public at IMIA's website. Work is currently being undertaken to explore the need for any update to the code, and undertake any changes.

\section{Official Journals}

Three scientific publications have been accorded the status of "an Official Jour- nal of the International Medical Informatics Association" since 2003: Methods of Information in Medicine and Applied Clinical Informatics (Schattauer Publishers, Stuttgart) and Elsevier Science's International Journal of Medical Informatics.

\section{Communications and Interaction}

IMIA continues to develop its communication capabilities through its website (http://www.imia.org). The site is undergoing expansion and development, and contains profiles of its members, working groups and activities. IMIA is constantly striving to improve the services it provides to its members and the informatics community in general by promoting free interaction among and between its member network and the bio-medical and health informatics community at large. Through input from the IMIA Social Media Working Group, further modes of interaction with and between IMIA members and the wider global health and biomedical informatics communities are being developed. IMIA has presences on social media sites, including Twitter (@IMIAtweets, @imia_medinfo), Facebook and LinkedIn.

\section{References}

1. Murray PJ. The IMIA Strategic Plan - Towards IMIA 2015. In: Geissbuhler A, Haux R, Kulikowski $\mathrm{C}$, editors, IMIA Yearbook of Medical Informatics 2008. Methods Inf Med 2008; 47 Suppl1:7-15.

2. Lorenzi N, Murray PJ, de Assis Moura Jr. L, Goh HM, Huesing S, Martin-Sanchez F, et al. Strategy in a Fishbowl: An Invitation to Determine the Shape of IMIA in 2015. Methods Inf Med 2006; 45 235-9.

3. Murray P, Haux R, Lorenzi N. Let a Thousand Flowers Bloom: Transition towards Implementation of the IMIA Strategic Plan. Methods Inf Med 2007; 46:625-8.

4. Haux R. IMIA and its Members: On Balancing Continuity and Transition in Biomedical and Health Informatics: President's Statement. Yearb Med Inform 2009: 1-6.

5. Mantas J, Ammenwerth E, Demiris G, Hasman A, Haux W, Hersh W, Hovenga E, et al. Recommendations of the International Medical Informatics Association (IMIA) on Education in Biomedical and Health Informatics: First Revision. Methods Inf Med 2010; 49. 